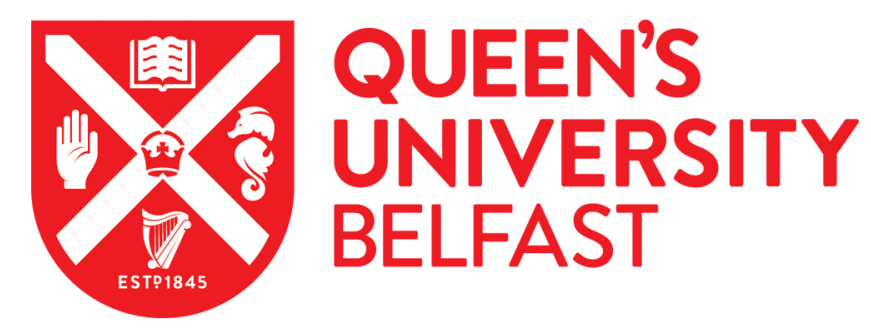

\title{
Cardiac glycosides and breast cancer risk: A systematic review and meta-analysis of observational studies
}

Karasneh, R. A., Murray, L. J., \& Cardwell, C. R. (2017). Cardiac glycosides and breast cancer risk: A systematic review and meta-analysis of observational studies. International Journal of Cancer, 140(5), 10351041. https://doi.org/10.1002/ijc.30520

Published in:

International Journal of Cancer

Document Version:

Peer reviewed version

Queen's University Belfast - Research Portal:

Link to publication record in Queen's University Belfast Research Portal

Publisher rights

Copyright Wiley 2016.

This work is made available online in accordance with the publisher's policies. Please refer to any applicable terms of use of the publisher.

\section{General rights}

Copyright for the publications made accessible via the Queen's University Belfast Research Portal is retained by the author(s) and / or other copyright owners and it is a condition of accessing these publications that users recognise and abide by the legal requirements associated with these rights.

Take down policy

The Research Portal is Queen's institutional repository that provides access to Queen's research output. Every effort has been made to ensure that content in the Research Portal does not infringe any person's rights, or applicable UK laws. If you discover content in the Research Portal that you believe breaches copyright or violates any law, please contact openaccess@qub.ac.uk. 


\title{
Cardiac glycosides and breast cancer risk: A systematic review and meta- analysis of observational studies
}

\author{
Reema A. Karasneh ${ }^{1}$, Liam J. Murray ${ }^{1,2}$, and Chris R. Cardwell ${ }^{1}$ \\ ${ }^{1}$ Cancer Epidemiology and Health Services Research Group, Centre for Public Health, \\ Queen's University Belfast, Belfast, Northern Ireland. \\ ${ }^{2}$ Centre of Excellence for Public Health (NI), Centre for Public Health, Queen's University \\ Belfast, Belfast, Northern Ireland.
}

Running Title: Cardiac glycosides and breast cancer risk

Corresponding author's contact information:

Dr. Chris R. Cardwell

Cancer Epidemiology and Health Services Research Group, Centre for Public Health, Queen's University Belfast. Institute of Clinical Sciences Block B, Queen's University Belfast, Royal Victoria Hospital, Grosvenor Road, Belfast, BT12 6BA. Phone: $+44(0) 28$ 90632620. Fax: +44(0)28 90235900. Email address (c.cardwell@qub.ac.uk).

Keywords: Epidemiology; Meta-analysis; Breast cancer; Cardiac glycosides.

Abbreviations used: HR: Hazard ratios; CIs: Confidence intervals; ER: Estrogen receptors; Mesh: Medical subject headings; OR: Odds ratio; HR: Hazard ratio; SIR: Standardised incidence ratio; RR: Rate ratio; NOS: Newcastle Ottawa scale; BMI: Body mass index; HRT: Hormone replacement therapy; C-C: Case -Control; NC-C: Nested case-control; CPRD: Clinical practice research datalink; CG: Cardiac glycosides; PM: Postmenopausal; NR: Not reported; FCR: Finnish cancer registry; SII: Social insurance institution; pop: population; HT: Hypertension; ER: Estrogen; NSAIDs: Non-Steroidal Anti-Inflammatory Drugs.

Article category: Research Article/ Cancer Epidemiology

Novelty and Impact: Cardiac glycosides are phytoestrogens and their use has been associated with increased risk of estrogen sensitive cancers. However, the association between their use and risk of breast cancer remains unclear. We investigated the association between cardiac glycosides use and the risk of breast cancer by systematically reviewing the published literature and performing meta-analyses. This study is the first comprehensive systematic review and meta-analysis to investigate the association between cardiac-glycosides use and risk of breast cancer. 


\begin{abstract}
Cardiac glycosides are phytoestrogens and have been linked to the risk of estrogen sensitive cancers such as uterus cancer. However, the association between use of cardiac glycosides and risk of breast cancer remains unclear. We investigated the association between cardiac glycosides use and the risk of breast cancer by systematically reviewing the published literature and performing meta-analyses. A comprehensive literature search was performed using MEDLINE, EMBASE, Web of Science and SCOPUS to identify all relevant articles published up to November 2015. Risk estimates, and accompanying standard errors, for the association between cardiac glycoside use and breast cancer were extracted from identified studies. Meta-analysis models were used to calculate a combined hazard ratio (HR), and 95\% confidence interval (CI), and to investigate heterogeneity between studies. In total, 9 studies were identified investigating cardiac glycosides use and risk of developing breast cancer. Overall, there was evidence to suggest an association between cardiac glycosides use and breast cancer risk (HR=1.34; 95\% CI 1.25, 1.44; $\mathrm{p}<0.001)$ with little variation in the association between studies $\left(\mathrm{I}^{2}=16 \%\right.$, $\mathrm{p}$ for heterogeneity $\left.=0.30\right)$. Results were little altered when analysis was restricted to studies with high quality scores or cohort studies. Overall, there was a 34\% increase in breast risk with use of cardiac glycosides but it is unclear whether this association reflects confounding or is causal. Further observational studies are required to examine this association particularly for estrogen receptor positive breast cancer and to explore the role of potential confounding variables.
\end{abstract}




\section{Introduction}

Cardiac glycosides (digoxin and digitalis) are phyto-estrogens ${ }^{1}$ and are used to treat heart failure and supra-ventricular arrhythmias (atrial fibrillation/flutter) ${ }^{2}$. Early animal studies indicate that cardiac glycosides may bind to estrogen receptors (ER) and have estrogenic effects ${ }^{1}$. In support of this, digoxin has been found to be associated with estrogen sensitive cancers such as uterus cancer ${ }^{3,4}$ and to induce gynecomastia in men ${ }^{5,6}$.

It has long been recognised that estrogen therapy increases breast cancer risk ${ }^{7-10}$, therefore the effect of cardiac glycosides on breast cancer risk is of some concern. Research into the association between cardiac glycosides and breast cancer risk began in the $1970 \mathrm{~s}{ }^{11}$. Since then numerous additional studies have been conducted. However this research is difficult to interpret because of the number of studies conducted, the different sizes and powers of these studies and the seemingly conflicting results ${ }^{12,13}$. Although an earlier observational study ${ }^{14}$, conducted a brief meta-analysis for digoxin and breast cancer risk, this meta-analysis only searched one bibliographic database (with a literature search which initially identified only 67 articles), did not report detailed characteristics of the included studies, did not investigate study quality and included two overlapping studies ${ }^{15,16}$.

Therefore, the aim of this study was to perform a systematic review using a wide and comprehensive search strategy to identify all relevant literature and to conduct a metaanalysis of the association between cardiac glycosides and breast cancer risk.

\section{Methods}

\section{Search strategy}

Studies were identified by searching four electronic databases; EMBASE (Reed Elsevier PLC, Amsterdam, Netherlands), MEDLINE (US National Library of Medicine, National Institutes of Health, Bethesda, Maryland, USA), Web of Science (Thomson Reuters, New York USA), and SCOPUS (Elsevier B V) from inception to November 2015.

The literature search was made with no restrictions. The MEDLINE search strategy used the following text words or Medical Subject Headings (Mesh): Breast neoplasms, breast, neoplasms, cancer, carcinoma, carcinomas, digoxin, digitoxin, cardiac glycosides, cardiac 
glycoside, digitalis, sodium potassium ATPase inhibitors, foxglove, cardiotonic steroid, bufadienolide, bufalin, cardenolide, proscillaridin. The full MEDLINE search is shown in Supplementary Table S1. Similar searches were conducted on the other electronic databases.

\section{Eligibility criteria}

Articles were screened independently by two investigators (RK, and CC). Articles were included if they met the following inclusion criteria: they reported a risk estimate (odds ratio (OR), hazard ratio (HR), standardised incidence ratio (SIR), or rate ratio (RR)) for the association between cardiac glycoside use and breast cancer in women. First, the articles retrieved from searches were screened by titles and abstracts and articles were excluded at this stage if they were obviously irrelevant. In cases were eligibility could not be determined via article abstracts, full text papers were requested and assessed. The reference lists of included studies were also hand searched. Finally, using Web of Science articles citing the identified studies were also searched to identify any further relevant articles. Finally, duplicate articles were excluded.

\section{Data extraction}

Data was independently extracted from all relevant studies by two investigators (RK, and CC) including information on author, year of publication, location, study population, followup in years, exposure ascertainment, type of cardiac glycosides used, classification of cardiac glycosides use (ever, never, former, current), outcome ascertainment, outcome reported and confounders adjusted for. In addition, studies that have provided results by estrogen receptor (ER) status (positive, negative, unknown) were examined. The Newcastle Ottawa Scale (NOS) ${ }^{17}$ was used to assess study quality with a cut-off of five used to define higher quality articles.

\section{Statistical analysis}

Risk estimates (ORs, HRs, SIRs, or RRs) and accompanying standard errors were extracted from each study for the association between cardiac glycoside use and breast cancer risk. In each study, the risk estimate (and standard error) that was adjusted for the most potential confounders was extracted. If not reported within studies, risk estimates were calculated using information provided where possible. Specifically, in a Swedish study no confidence intervals (CI) were reported and therefore CIs were calculated from data reported in Table 1 of the Stenkvist paper ${ }^{18}$. Also, in the Friedman study CIs were calculated based upon the 
observed and expected number of breast cancer cases based upon a Poisson exact confidence interval as calculated by STATA ${ }^{19}$.

By necessity, ORs (from two studies), HRs (from 2 studies), RRs (from 3 studies) and SIR (from 2 studies) were combined. However, the OR should approximate a HR and a RR when the disease of interest is not common ${ }^{20}$. As between study heterogeneity was anticipated, random effects models were used to produce an overall pooled HR with 95\% confidence intervals (CI) ${ }^{21}$. Heterogeneity among studies was investigated using a Chi-squared test and I-squared statistic $\left(\mathrm{I}^{2}\right)^{22}$. Sensitivity analyses were conducted to investigate whether results differed on the basis of study design (case-control or nested case-control/cohort) or quality score (NOS score of five or more). To check for publication bias, funnel plots were produced to investigate evidence for asymmetry. All meta-analyses were conducted in Review Manager version 5.1 (Nordic Cochrane Centre, Copenhagen, Denmark).

\section{Results}

\section{Literature search}

The initial database search ascertained 1,171 articles, of which 1,113 were excluded after screening of titles and abstracts (Figure 1). The remaining 58 potentially relevant articles were screened by full text for inclusion. Duplicate articles $(n=37)$, conference abstracts $(n=1)$ and review articles $(n=6)$ were excluded. Additional exclusions included those studies that included male breast cancer patients $(n=2)$, and that reported relapse/recurrence $(n=2)$ or mortality $(n=2)$ outcomes. A further 2 studies were identified from hand searching the reference list of included articles ${ }^{12,23}$. Two articles were based upon the one study ${ }^{15,16}$ and so the later larger study was retained ${ }^{15}$. Therefore 9 studies met the inclusion criteria ${ }^{12-}$ $15,18,19,23-25$

\section{Study characteristics}

Characteristics of the included studies are shown in Table 1. There were three case-control studies, including one nested case-control study, and an additional six cohort studies. Five studies originated in Europe; one in the UK ${ }^{13}$, four in Scandinavia (Denmark, Norway, Finland and Sweden) ${ }^{15,18,23,25}$. Three were conducted in the USA ${ }^{12,14,24}$ and for one study the 
origin was not reported ${ }^{19}$. Breast cancer cases were ascertained through cancer registries in four articles.

Methods of exposure ascertainment varied across studies (Table 1). Eight of the 9 studies solely used medical records, register data, or questionnaire. Only one study used a combination of questionnaire and medical records. Digoxin use was investigated in three studies, while digitalis was the main exposure in five studies and the remaining study investigated digitoxin (Table 2). Quality scores calculated for each study are shown in table 1. Seven studies had high quality scores $(\geq 5)^{13-15,18,23-25}$.

All but one of the cohort studies accounted for age in their analyses ${ }^{12}$ and all of the casecontrol studies matched controls to cases by age. The confounders accounted for in analyses varied markedly across studies with some adjusting for few or no confounders whilst others adjusted for a wide range of confounders including body mass index (BMI), hormone replacement therapy (HRT), and medication use (see Table2).

\section{Main findings}

Overall there was an increase in rate of breast cancer among cardiac glycosides users compared with non-users (HR=1.34; 95\% CI 1.25, 1.44; $\mathrm{p}<0.00001)$ with little evidence of heterogeneity $\left(\mathrm{I}^{2}=16 \%\right.$, $\mathrm{p}$ for heterogeneity $=0.30$ ) (Figure 2$)$. Funnel plots revealed no evidence of asymmetry which would be indicative of publication bias (Supplementary Figure S1).

The association was similar in studies which investigated digoxin (pooled $\mathrm{HR}=1.29$; 95\% CI 1.11, 1.51; $\mathrm{p}=0.0009$ ) or studies which investigated digitalis (pooled HR=1.42; 95\% CI 1.23, 1.63; $\mathrm{p}<0.00001$ ). Repeating the analysis in higher quality studies (ie. removing two studies that scored less than five on the NOS) the main finding was little altered (pooled $\mathrm{HR}=1.31$; 95\% CI 1.19, 1.44; $\mathrm{p}<0.00001)$ and the heterogeneity increased slightly $\left(\mathrm{I}^{2}=30 \%, \mathrm{p}\right.$ for heterogeneity=0.02). When restricting the analysis to cohort studies the estimate was slightly more marked (HR=1.39; 95\% CI 1.33, 1.46; $\mathrm{p}<0.00001)$ with no heterogeneity observed $\left(\mathrm{I}^{2}=0 \%\right.$, $\mathrm{p}$ for heterogeneity $\left.=0.95\right)$.

Only two of the 9 studies investigated estrogen receptor status. Digoxin users appeared to have stronger associations with estrogen receptor positive breast cancer $(\mathrm{RR}=1.35$; 95\% CI 1.26, 1.45 and $\mathrm{HR}=1.46$; $95 \%$ CI 1.10, 1.95) than estrogen receptor negative breast cancer $\left(\mathrm{RR}=1.20 ; 95 \% \mathrm{CI} 1.03,1.40\right.$ and $\mathrm{HR}=1.12 ; 95 \%$ CI 0.52, 2.37) respectively $^{14,15}$. 


\section{Discussion}

Our study provides evidence that women using cardiac glycosides have increased breast cancer risk by 34\% (95\% CI 1.25, 1.44). This association was fairly consistent across studies and most of the inconsistency reflected the magnitude of the increase, as all studies observed increased risks of breast cancer in cardiac glycoside users, though in some this increase was small and not significant. These findings were little altered when investigating cohort studies or higher quality studies.

The cause of the increased breast cancer risk in women using cardiac glycosides is unclear. As with all observational studies, we cannot rule out the effect of confounding. Our metaanalysis is based upon the adjustment for confounders conducted within each original study but these adjustments were not consistent across studies and a number of studies 15,18,19,23-25 adjusted for few confounders. Only one study used methods based upon restriction ${ }^{13}$, that have been recommended to reduce the risk of confounding ${ }^{26}$. In that study ${ }^{13}$, the cohort was restricted solely to patients with cardiac glycoside indications (in particular congestive heart failure, atrial fibrillation, atrial flutter, and other supra-ventricular tachycardia) and there was no association between digoxin and breast cancer risk (OR=1.07; 95\% CI 0.90, 1.26). This is arguably a better analysis because there are shared risk factors between cardiovascular disease and breast cancer which may have less effect on this comparison as digoxin users are compared with non-users with similar indications. Alternatively, the association may not reflect confounding but could be real. Cardiac glycosides are phyto-estrogens ${ }^{1}$ and may have estrogenic effects ${ }^{27,28}$, although the evidence that digoxin and digitoxin act through an estrogen-receptor mediated mechanism is limited, as noted in recent IARC monographs ${ }^{29}$. If real this estrogenic effect of cardiac glycosides could increase breast cancer risk similar to increases seen for estrogen hormone therapy ${ }^{7-10}$. In support of this, there were stronger associations for digoxin users with estrogen receptor positive breast cancer compared with estrogen receptor negative breast cancer ${ }^{14,15}$. However, there is a lack of such information available and future studies should include ER receptor status of breast cancer patients in cardiac glycosides users. Moreover, there is a need for further observational studies with comprehensive investigation of methods to adjust for confounding, for instance by restricting the population to patients with cardiac glycoside indications, to investigate whether the increased risks observed in our meta-analysis are real or reflect confounding. Another weakness was that studies reported different measures of association (including ORs, HRs, 
RRs), but by necessity these were combined. However, it is reassuring that despite this there was little heterogeneity ${ }^{20}$.

Our meta-analysis results are similar to the brief meta-analysis conducted by Ahern et al. which observed a 37\% increase in breast cancer risk with digoxin use ${ }^{14}$, but their study searched only one database and only included 6 articles, and erroneously included two studies which overlapped ${ }^{15,16}$. Furthermore, their study did not report in detail characteristics of the individual studies (such as confounders), conduct quality scoring, or investigate funnel plots. Our findings are also similar to the conclusion of the narrative review contained in the most recent IARC monograph ${ }^{29}$ but it is worth noting that our review includes five additional studies and this IARC monograph did not contain a formal meta-analysis.

In conclusion; in this systematic review and meta-analysis, women using cardiac glycosides had an increased risk of developing breast cancer. However, additional studies are required to examine this association particularly for estrogen receptor positive breast cancer and to explore whether this increased risk would persist after additional adjustment for potential confounding.

\section{Financial support:}

During the period of this study, $\mathrm{RK}$ was a $\mathrm{PhD}$ candidate at Queen's University Belfast funded by Yarmouk University, Jordan. The funders had no role in the study design; analysis, and interpretation of data; or the decision to submit for publication.

\section{Disclosures:}

The authors declare that they have no conflict of interest. 


\section{References}

1. Biggar RJ. Molecular pathways: digoxin use and estrogen-sensitive cancers--risks and possible therapeutic implications. Clin cancer Res 2012;18:2133-7.

2. Joint Formulary Committee. British national formulary (BNF). 67th ed. London: BMJ group and Pharmaceutical Press, 2014. 1144p

3. Biggar R, Wohlfahrt J, Melbye M. Digoxin use and the risk of cancers of the corpus uteri, ovary and cervix. Int J Cancer 2012;131:716-21.

4. Biggar RJ. Molecular pathways: Digoxin use and estrogen-sensitive cancers - Risks and possible therapeutic implications. Clin cancer Res 2012;18:2133-7.

5. $\quad$ Braunstein GD. Gynecomastia. N Engl J Med 1993;328:490-5.

6. Dickey RP, Stone SC. Drugs that affect the breast and lactation. Clin Obstet Gynecol 1975;18:95-111.

7. Collaborative Group on Hormonal Factors in Breast Cancer. Breast cancer and hormone replacement therapy: collaborative reanalysis of data from 51 epidemiological studies of 52,705 women with breast cancer and 108,411 women without breast cancer. Lancet (London, England) 1997;350:1047-59.

8. Rossouw JE, Anderson GL, Prentice RL, LaCroix AZ, Kooperberg C, Stefanick ML, Jackson RD, Beresford SAA, Howard B V, Johnson KC, Kotchen JM, Ockene J. Risks and benefits of estrogen plus progestin in healthy postmenopausal women: principal results From the Women's Health Initiative randomized controlled trial. JAMA 2002;288:321-33.

9. Beral V. Breast cancer and hormone-replacement therapy in the Million Women Study. Lancet (London, England) 2003;362:419-27.

10. Cuzick J. Hormone replacement therapy and the risk of breast cancer. Eur J Cancer 2008;44:2344-9.

11. Stenkvist B, Bengtsson E, Eriksson O, Holmquist J, Nordin B, Westman-Naeser S. Cardiac glycosides and breast cancer. Lancet 1979;1:563.

12. Hartz AJ, He T. Cohort study of risk factors for breast cancer in post menopausal 
women. Epidemiol Health 2013;35:e2013003.

13. Couraud S, Dell'Aniello S, Bouganim N, Azoulay L. Cardiac glycosides and the risk of breast cancer in women with chronic heart failure and supraventricular arrhythmia. Breast Cancer Res Treat 2014;146:619-26.

14. Ahern TP, Tamimi RM, Rosner BA, Hankinson SE. Digoxin use and risk of invasive breast cancer: evidence from the Nurses’ Health Study and meta-analysis. Breast Cancer Res Treat 2014;144:427-35.

15. Biggar RJ, Wohlfahrt J, Oudin A, Hjuler T, Melbye M. Digoxin use and the risk of breast cancer in women. J Clin Oncol 2011;29:2165-70.

16. Ahern TP, Lash TL, Sørensen HT, Pedersen L. Digoxin treatment is associated with an increased incidence of breast cancer: a population-based case-control study. Breast Cancer Res 2008;10:R102.

17. GA Wells, B Shea, D O’Connell, J Peterson, V Welch, M Losos PT. The NewcastleOttawa Scale (NOS) for assessing the quality of nonrandomised studies in metaanalyses. 2016 [cited 2016 Mar 8];Available from: http://www.ohri.ca/programs/clinical_epidemiology/oxford.asp

18. Stenkvist B, Bengtsson E, Eklund G, Eriksson O, Holmquist J, Nordin B, WestmanNaeser S. Evidence of a modifying influence of heart glucosides on the development of breast cancer. Anal Quant Cytol 1980;2:49-54.

19. Friedman GD. Digitalis and breast cancer. Lancet 1984;2:875.

20. Kirkwood BR, Sterne JAC. Essential Medical Statistics. 2nd Editio. Oxford: Blackwell Science, 2003. 243p

21. DerSimonian R, Laird N. Meta-analysis in clinical trials. Control Clin Trials 1986;7:177-88.

22. Higgins JPT, Thompson SG, Deeks JJ, Altman DG. Measuring inconsistency in metaanalyses. BMJ 2003;327:557-60.

23. Haux J, Klepp O, Spigset O, Tretli S. Digitoxin medication and cancer; case control and internal dose-response studies. BMC Cancer 2001;1:11. 
24. Danielson DA, Jick H, Hunter JR, Stergachis A, Madsen S. Nonestrogenic drugs and breast cancer. Am J Epidemiol 1982;116:329-32.

25. Aromaa A, Hakama M, Hakulinen T, Saxén E, Teppo L, Idä lan-Heikkilä J. Breast cancer and use of rauwolfia and other antihypertensive agents in hypertensive patients: a nationwide case-control study in Finland. Int J Cancer 1976;18:727-38.

26. Schneeweiss S, Patrick AR, Stürmer T, Brookhart MA, Avorn J, Maclure M, Rothman KJ, Glynn RJ. Increasing levels of restriction in pharmacoepidemiologic database studies of elderly and comparison with randomized trial results. Med Care 2007;45:S131-42.

27. Rifka SM, Pita JC, Loriaux DL. Mechanism of interaction of digitalis with estradiol binding sites in rat uteri. Endocrinology 1976;99:1091-6.

28. Rifka SM, Pita JC, Vigersky RA, Wilson YA, Loriaux DL. Interaction of digitalis and spironolactone with human sex steroid receptors. J Clin Endocrinol Metab 1978;46:338-44.

29. International Agency for Research on Cancer. Digoxin. In: 108 Carcinogenicity of some drugs and herbal products, Lyon, France: IARC, 2015. 


\section{Tables titles:}

Table1 Characteristics of studies of cardiac glycosides use and breast cancer risk

Table 2 Summary of included studies of cardiac glycosides use and breast cancer risk

\section{Figure titles:}

Fig 1 Flow chart of study selection

Fig 2 Forest plot of the cardiac glycosides and breast cancer risk

\section{Supplementary material:}

Supplementary material 1 (PDF 107 KB) Table S1 Presenting the Medline search string

Supplementary material 2 (PDF 109 KB) Figure S1 Showing the Funnel plot for cardiac glycosides use and risk of breast cancer. 
Table 1. Characteristics of studies of cardiac glycosides use and breast cancer risk

\begin{tabular}{|c|c|c|c|c|c|c|}
\hline Author (year), location & Design & $\begin{array}{c}\text { Exposure period } \\
\text { (years) }\end{array}$ & Study population & Breast cancer ascertainment & Exposure source & $\begin{array}{l}\text { NOS } \\
\text { score }\end{array}$ \\
\hline Couraud et al (2014), UK [13] & NC-C & 22 & $\mathrm{CPRD}$ (CG related indication) ${ }^{\mathrm{a}}$ & Medical records & Medical records & 8 \\
\hline Ahern et al (2014), US [14] & Cohort & 16 & Nurses’ Health study (PM) & Questionnaires \& medical records & Biennially self-reported questionnaires & 7 \\
\hline Hartz et al (2013), US [12] & Cohort & 13 & Women’s health initiative (PM) & Self-administered self-report & Self-administered self-report & 3 \\
\hline Biggar et al (2011), Denmark [15] & Cohort & 13 & Danish Prescription Database & Danish cancer registry & Prescription registry & 8 \\
\hline Haux et al (2001), Norway [23] & Cohort & 10 & Norwegian population & Norwegian cancer registry & Digitoxin lab database & 5 \\
\hline Friedman (1984) [19] & Cohort & 4 & NR & NR & Computer stored pharmacy records & 2 \\
\hline Danielson (1982), US [24] & Cohort & 3 & Group health cooperative (PM) & NR & Group health records & 5 \\
\hline Stenkvist (1980), Sweden [18] & $\mathrm{C}-\mathrm{C}$ & NR & Swedish Population & Computerized population register & Questionnaire and hospital records & 5 \\
\hline Aromaa et al (1976), Finland [25] & $\mathrm{C}-\mathrm{C}$ & NR & FCR \& SII’s pop. register (HT) & Finnish cancer registry & Register for HT prescriptions & 5 \\
\hline
\end{tabular}

Table 2. Summary of included studies of cardiac glycosides use and breast cancer risk

\begin{tabular}{|c|c|c|c|c|c|}
\hline Author (year), location & Comparison & $\begin{array}{l}\text { No. of breast } \\
\text { cancer }^{\text {cases }}\end{array}$ & $\begin{array}{l}\text { No. of non- } \\
\text { breast cancer } \\
\text { controls }^{\mathbf{b}}\end{array}$ & $\begin{array}{l}\text { Risk measurement } \\
(95 \% \mathrm{CI})\end{array}$ & Adjustments \\
\hline Couraud et al (2014), UK [13] & Digoxin user vs never user & 898 & 52,556 & OR=1.07 $(0.90,1.26)$ & $\begin{array}{l}\text { (Matched on Age, date of cohort entry, and duration of } \\
\text { follow-up), smoking, BMI, CG-related indication, HRT, } \\
\text { estrogen-based contraceptive drug, statins, aspirin, oral } \\
\text { anticoagulants and anti-platelets, NSAIDs, Anti- } \\
\text { hypertensive drugs, and anti-diabetic drugs. }\end{array}$ \\
\hline Ahern et al (2014), US [14] & Digoxin current user vs. never & 4,576 & 70,394 & $\mathrm{HR}=1.40(1.18,1.65)$ & Age, height, BMI, age (at menarche, menopause, first \\
\hline
\end{tabular}


birth and parity), alcohol, postmenopausal hormones use, family history, personal history of benign breast disease, mammography screening in the past 2 years, aspirin, ibuprofen, cholesterol-lowering drugs, and tamoxifen.

Hartz et al (2013), US [12]

Biggar et al (2011), Denmark [15]

Haux et al (2001), Norway [23]

Friedman (1984) [19]

Danielson (1982), US [24]

Stenkvist (1980), Sweden [18]

Aromaa et al (1976), Finland [25]
Digitalis ever user vs. non-user

NR

49,016 user

Digitoxin user versus non-user (based upon expected breast cancer from national cancer rates

Digitalis ever user vs. expected user

Digitalis glycosides user vs. nonuser

Digitalis ever user vs. non-user

179

Any digitalis ever user vs nonuser
NR

$2,067,013$

4,969

143,371

NR

179

109
$H R=1.46(1.24,1.72)$

$R R=1.39(1.32,1.46)$

$\mathrm{SIR}=1.25(0.95,1.62)$

$\mathrm{SIR}=1.21(0.74,1.87)$

$\mathrm{RR}=1.30(0.7,2.2)$

$\mathrm{OR}=1.39(0.76,2.57)$

$\mathrm{RR}=1.33(0.73,2.48)$
Age, calendar period

Matched on age, year of birth

Age-sex standardised

Age

Matched on age

Abbreviations: NR: not reported; BMI: Body Mass Index; CG: Cardiac glycosides; HRT: Hormone Replacement Therapy; ER: Estrogen; NSAIDs: Non-Steroidal Anti-Inflammatory Drugs.

${ }^{\text {a }}$ Number of cases in study population regardless of medication use.

${ }^{\mathrm{b}}$ Number of controls in study population regardless of medication use. 


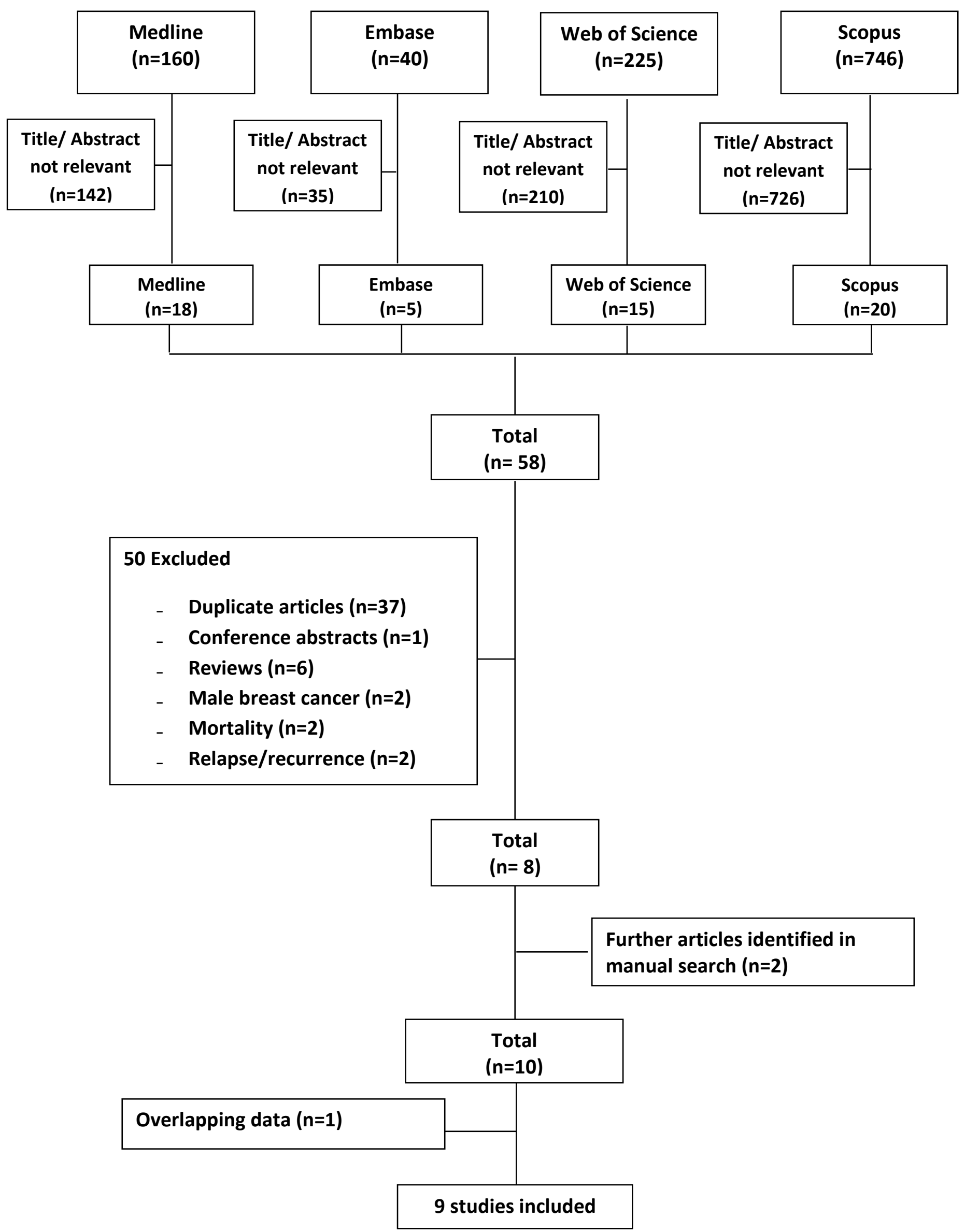




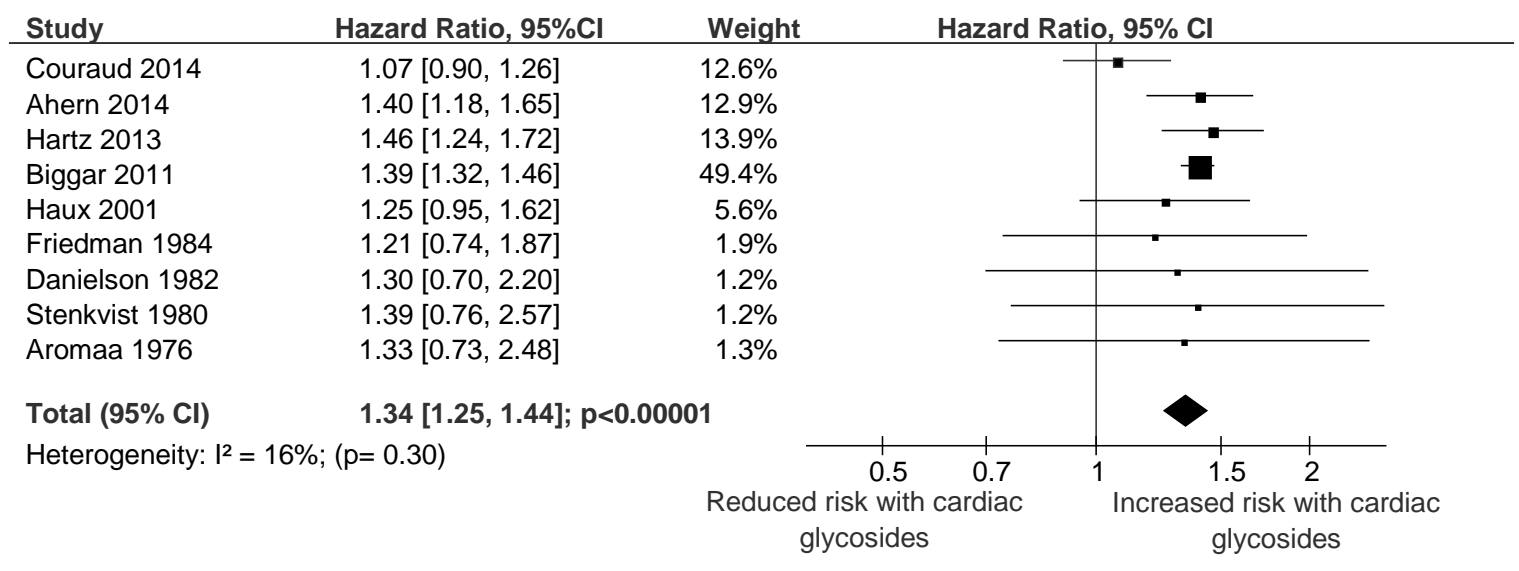

